\title{
Cardiac teleconsulting in the time of COVID-19 global pandemic: The "Antonio Cardarelli" Hospital project
}

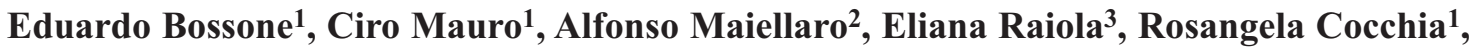 \\ Brigida Ranieri $^{4}$, Chiara Sepe ${ }^{1}$, Valentina Capone ${ }^{1}$, Salvatore Chianese ${ }^{1}$, Renato Maramaldi ${ }^{1}$, \\ Enrico Pasquale Acerra ${ }^{5}$, Gaetano Mirto ${ }^{6}$, Sergio Lodato ${ }^{7}$, Giuseppe Russo ${ }^{8}$, Giuseppe Longo 9 \\ ${ }^{1}$ Cardiology Unit, A. Cardarelli Hospital, Naples; ${ }^{2}$ Medicine and Clinical Risk Unit, A. Cardarelli Hospital, Naples; \\ ${ }^{3}$ Health Department, A. Cardarelli Hospital, Naples; ${ }^{4}$ IRCCS SDN, Naples; ${ }^{5}$ GESAN Srl, San Nicola La Strada (CE); \\ ${ }^{6}$ Clinical Engineering Division, A. Cardarelli Hospital, Naples; ${ }^{7}$ Clinical Epidemiology and Statistics, A. Cardarelli \\ Hospital, Naples; ${ }^{8}$ Chief Medical Officer A. Cardarelli Hospital, Naples; ${ }^{9}$ CEO A. Cardarelli Hospital, Naples, Italy
}

\section{Dear Editor,}

Teleconsulting - defined as real-time consultation between doctors by exploiting video conferencing technology over the Internet network - is exponentially being implemented through the western world lastly triggered by COVID-19 pandemic [1-3]. The Cardiology Unit of Cardarelli Hospital, Naples, Italy, serves as cardiac consultations to 43 Units including perioperative cardiovascular risk assessment for noncardiac surgery, cardio-oncology and COVID-19 patients. During the last 2 years (2019-2020) it has been registered a substantial number of cardiac consultations $(n=10,064$; Figure 1). Thus, the Cardarelli Hospital has designed the Teleconsulting Cardiology (TL-CARD) Project in order to improve

Correspondence: Eduardo Bossone, MD, PhD, Cardiology Division, A. Cardarelli Hospital

Via A. Cardarelli 9, 80131 Naples, Italy.

Tel. +39.081.7472143 - Fax: +39.081.7473068.

E-mail: eduardo.bossone@aocardarelli.it

Keywords: teleconsulting; COVID-19; cardiac consultation; case manager; web-based system.

Authors' contributions: EB, study design; EB, BR, data analysis. All authors have drafted the work and substantively revised it, read and approved the final version of the manuscript and agreed to be accountable for all aspects of the work.

Conflict of interest: The authors declare that they have no competing interests, and all authors confirm accuracy.

Funding: This research received no specific grant from any funding agency in the public, commercial, or not-for-profit sectors.

Received for publication: 25 January 2021.

Accepted for publication: 26 Janaury 2021.

${ }^{\circ}$ Copyright: the Author(s), 2021

Licensee PAGEPress, Italy

Monaldi Archives for Chest Disease 2021; 91:1779

doi: 10.4081/monaldi.2021.1779

This article is distributed under the terms of the Creative Commons Attribution Noncommercial License (by-nc 4.0) which permits any noncommercial use, distribution, and reproduction in any medium, provided the original author(s) and source are credited. the performance of cardiac consultations and to reduce, at the same time, the risk SARS-CoV-2 transmission among healthcare workers and patients (Figure 2). A dedicated case manager nurse supervises the system organization and functioning. All the cardiac consultations are requested by the patient's caring physician through a webbased system. Subsequently, the cardiologist, based on available electronic charts information (including diagnosing testing results, invasive and non-invasive procedures images, etc..) identifies three distinct clinical scenarios potentially requiring cardiac advices:

Patient hemodynamically stable: the cardiologist after consulta-

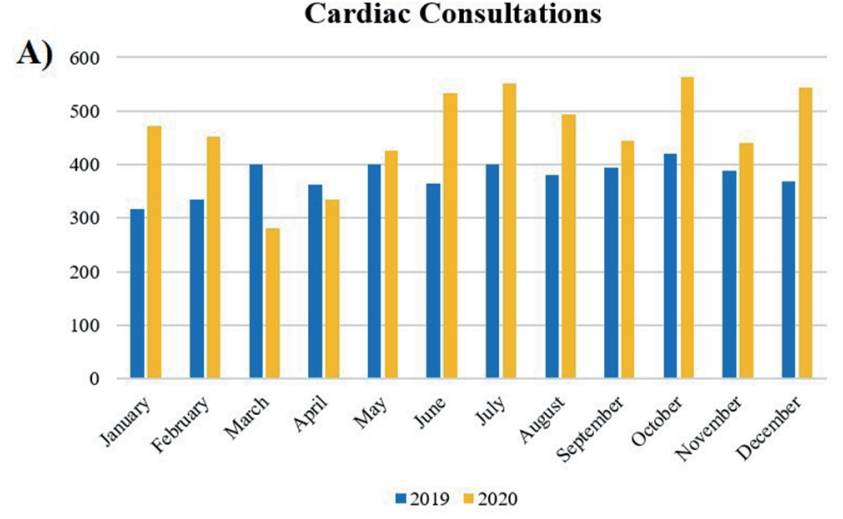

B)

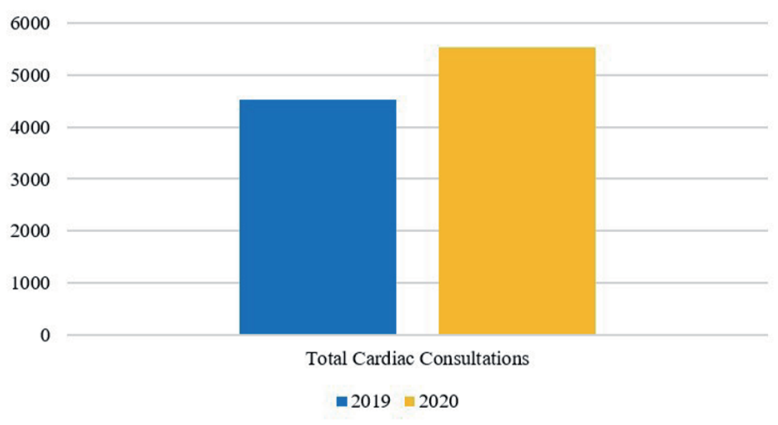

Figure 1. Number of cardiac consultations over the last two years (2019-2020), stratified by months (A) and years (B). In 2020, there is an increase in cardiac consultations compared to 2019 in all months except for March and April related to the first COVID19 outbreak in the Naples area. 


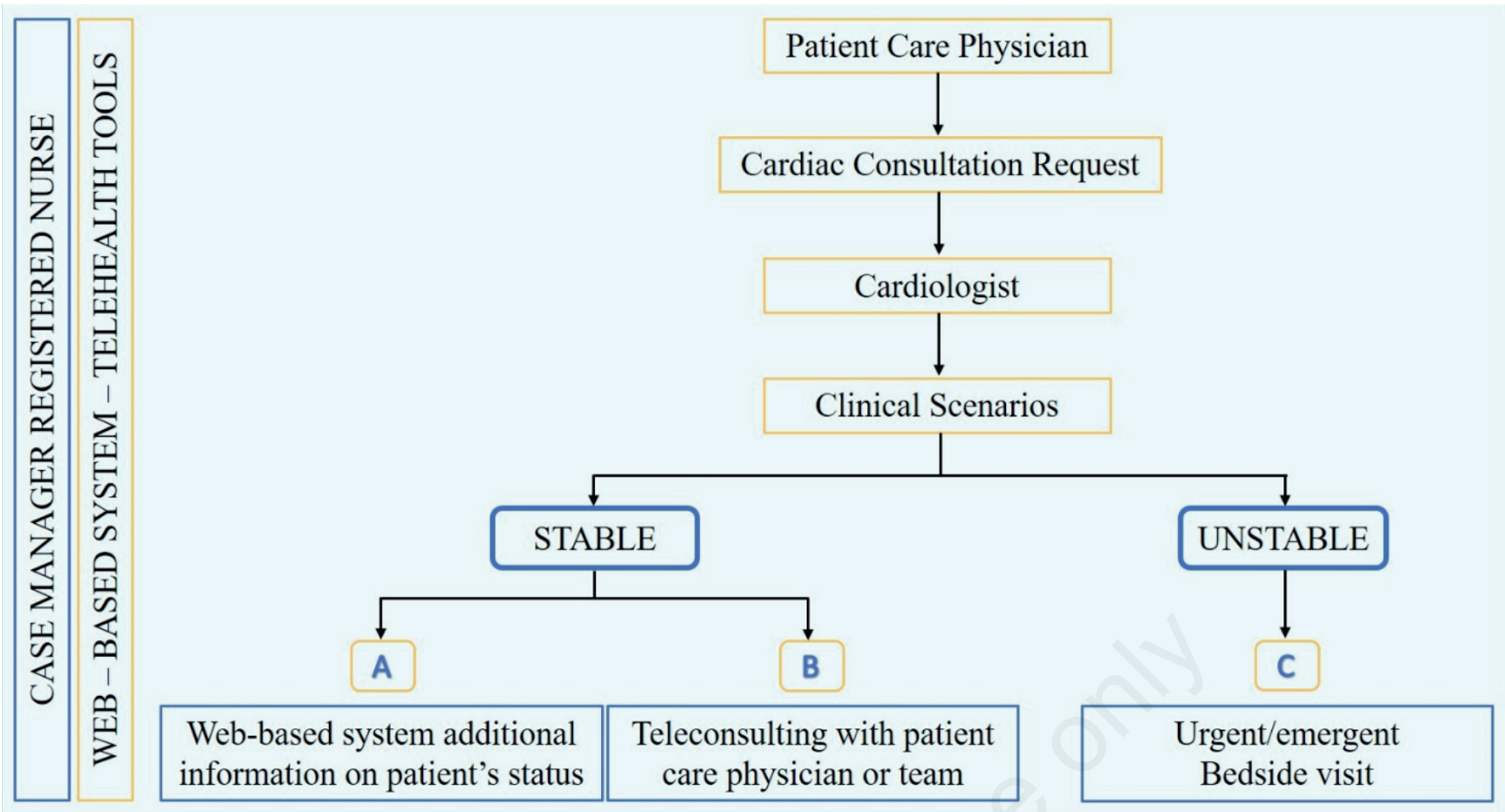

Figure 2. The Teleconsulting Cardiology (TL-CARD) algorithm designed by the Cardarelli Hospital (Naples, Italy) in order to improve the performance of cardiac consultations and to reduce the risk of SARS-CoV-2 transmission among healthcare workers and patients.

tion of electronic chart (within $24 \mathrm{~h}$ ) may request additional anamnestic/clinical information (i.e., functional status, presence of major co-morbidities) and/or blood biomarkers (namely natriuretic peptides, troponins and D-dimer) before any further step is made.

Patient hemodynamically stable where a "second cardiology opinion" (within $24 \mathrm{~h}$ ) may be delivered through conferencing technology with the physician team in charge of the patient in order to define diagnostic/therapeutic clinical decision process.

Patient hemodynamically unstable [as in the case of acute or recent ( $\leq 30$ days) coronary syndromes, myocardial infarction in non-obstructive coronary artery disease, acute pulmonary embolism, transient ischemic attack or stroke; acute heart failure, symptomatic cardiac valve disease, tachyarrhythmias or bradyarrhythmias associated with hypotension] requiring urgent/emergent cardiac specialist bedside attention (Figure 2).

The cardiac teleconsulting implementation 24 out of 24 throughout the year 2021 it is expected to guarantee through telehealth tools timely specialists' advices (integrated multidisciplinary concept-approach) in order to provide best practice patients' care respecting physical distancing.

\section{References}

1. Ministero della Salute. [Linee di indirizzo nazionali sulla Telemedicina (Marzo 2014) e Rapporti ISS COVID-19 n. $12 / 2020$. Indicazioni ad interim per servizi assistenziali di telemedicina durante l'emergenza sanitaria COVID-19].[in Italian]. Version 13 Aprile 2020. Available from: http://www.salute.gov.it/portale/nuovocoronavirus/dettaglioN otizieNuovoCoronavirus.jsp?lingua $=$ italiano $\&$ menu=notizie $\&$ $\mathrm{p}=$ dalministero $\& \mathrm{id}=4503$

2. Ting DSW, Carin L, Dzau V, Wong TY. Digital technology and COVID-19. Nat Med 2020;26:459-61.

3. Weinstein RS, Krupinski EA, Doarn CR. Clinical examination component of telemedicine, telehealth, mHealth, and connected health medical practices. Med Clin North Am 2018;102:533-44. 